Diets low in allergens or food additives are on trial both in the United States and in Britain. Keeping to such diets entails great maternal determination and some social hardship, but some evidence has been produced that food colourings may be a toxic factor affecting some hyperactive children. ${ }^{7}$

While it is unlikely that the pervasively hyperactive child's behaviour is caused by parental behaviour, ${ }^{12}$ the child and his family need to be helped to understand the disorder and to avoid the scapegoating and rejection which sometimes occur. Family therapy techniques appear to offer the most promising psychotherapeutic approach to helping the handicapped child. ${ }^{13}$

The prognosis for hyperkinetic children is poor in adolescence. The hyperactivity diminishes, but antisocial and cognitive difficulties persist and increase. One controlled follow-up study which extended beyond adolescence, however, gives a more hopeful picture. Weiss and her colleagues ${ }^{9}$ followed up for 10 years 75 children who fitted the criteria of pervasive hyperkinetic syndrome and 44 matched controls and found that, while hyperactive subjects continued to be more impulsive and restless and had more car accidents, there was no excess of antisocial behaviour, severe psychopathology, job instability, or drug abuse compared with the control group. Virtually none of these patients had had any form of effective drug treatment.

Werry, ${ }^{13}$ reviewing Cantwell's book ${ }^{14}$ on the hyperactive child, ends by saying "true or false, the notion of the hyperactive child has been one of the most heuristic in child psychiatry since Bowlby's concept of maternal deprivation. . . . That alone makes it a good scientific concept ... the fact that many American doctors overdiagnose hyperactivity and overprescribe stimulants is no more an argument against either the diagnosis or its treatment than is the gross misuse of penicillin ... an argument against careful bacteriological diagnosis and antibiotic treatment."
Good child psychiatric practice now requires the identification of children with pervasive hyperactivity severe enough to interfere with functioning and a pragmatic approach to treatment which embraces the child and his family.

\section{DORA BLACK}

Consultant Child Psychiatrist,

Edgware General Hospital,

Middlesex HA8 OAD

${ }^{1}$ Cantwell DP. Hyperkinetic syndrome. In: Rutter M, Hersov L, eds. Child psychiatry: modern approaches. London: Blackwell Scientific Publications, 1977.

2 Rutter M, Shaffer D, Shepherd M. A multi-axial classification of child psychiatric disorders. Geneva: WHO, 1975.

${ }^{3}$ Edwards G. Diagnosis of schizophrenia: an Anglo-American comparison. Br f Psychiatry 1972;120:385-90.

- Sandberg ST, Rutter M, Taylor E. Hyperkinetic disorder in psychiatric clinic attenders. Dev Med Child Neurol 1978;20:279-99.

${ }^{5}$ Schachar R, Rutter M, Smith A. The characteristics of situationally and pervasively hyperactive children: implications for syndrome definition. f Child Psychol Psychiatry 1981 ;22:375-92.

6 Taylor E. Food additives, allergy and hyperkinesis. $f$ Child Psychol Psychiatry 1979;20:357-64.

7 Swanson JM, Kinsbourne M. Food dyes impair performance of hyperactive children on a laboratory learning test. Science 1980;207:1485-6.

${ }^{8}$ Barkley RA. A review of stimulant drug research with hyperactive children. f Child Psychol Psychiatry 1977;18:137-65.

9 Weiss G, Hechtman L, Perlman T, Hopkins J, Wener A. Hyperactives as young adults. A controlled prospective ten-year follow-up of 75 children. Arch Gen Psychiatry $1979 ; 36: 675-81$.

${ }^{10}$ Christensen D-E, Sprague RL. Reduction of hyperactive behaviour by conditioning procedures alone and combined with methylphenidate. Behav Res Ther 1973;11:331-4.

11 Douglas VI, Parry P, Marton P, Garson C. Assessment of a cognitive training program for hyperactive children. $\mathcal{F}$ Abnorm Child Psychol $1976 ; 4: 389-410$

12 Humphries T, Kinsbourne M, Swanson J. Stimulant effects on co-operation and social interaction between hyperactive children and their mothers. f Child Psychol Psychiatry 1978;19:13-22.

13 Werry JS. Critical notice. $\mathcal{f}$ Child Psychol Psychiatry 1977;18:195-6.

${ }^{14}$ Cantwell DP. The hyperactive child: diagnosis, management, current research. New York: Spectrum Publications, 1975.

\title{
Personal Review
}

\section{Schools of public health}

\author{
ROY M ACHESON
}

Throughout the world there are probably some 50 schools of public health, 21 of them in the Americas. ${ }^{1}$ All have contributed notably to the health of the country in which they are located and usually far more broadly too. W $\mathrm{H}$ Welch ${ }^{2}$ - the creator and first dean of Johns Hopkins School of Medicine and later the founder of Johns Hopkins School of Hygiene in 1918 - had enough trust in their potential to encourage their dissemination with generous support from the Rockefeller Foundation. "Merely from a mercenary and commercial point of view it is for the interest of the community to take care of the health of the poor," he declared. "Philanthropy assumes a totally different aspect in the eyes of the world when it is able to demonstrate that it pays to keep the people healthy. ... It is estimated, and of course such an estimate can be only a rough one, that nearly 100000 deaths occur annually in this country from preventable causes. For each death there are of course several cases of illness not fatal, due to preventable causes. One can form from such a statement some idea of the enormous loss of money and productive labour which we suffer from preventable causes of illness and death."

The purpose of schools of public health was achieving the ends spelt out by Welch. He looked on two of the most important as being his own school in Baltimore and from 1929 the London School of Hygiene and Tropical Medicine. He told his old Yale Medical School classmates in 1920 that he had "retired from my chair in pathology in Johns Hopkins University to assume a new kind of work ... to me extremely interesting and somewhat novel. ... Laboratories and institutes of hygiene have existed as parts of medical schools, but the conception here is an independent faculty, and independent school, as part of a university existing side by side with the other faculties of the university, particularly the medical faculty 
based upon the view that the time has come for specialised training for those who desire to enter into that field of work. The great opportunity in... so-called industrial medicine (and) industrial hygiene ... rests upon such a body of scientific knowledge."

The goals Welch had in mind were very much those which he had ascribed to his own school in North Wolfe Street, Baltimore, and are quoted above. In London there were very important differences, for the natural attachment of the country to its empire had stimulated research and teaching in tropical medicine. The London School of Hygiene and Tropical Medicine did not incorporate the Ross Institute as an allied but semi-autonomous body until 1934, five years after its opening. This strengthened the tropical side of the school, which therefore had responsibility not only for the subjects which Welch felt required separate identity but for the whole gamut of health and prevention in the tropics.

Despite the visionary thinking that lay behind the enormous investment of the Rockefeller Foundation in schools of public health throughout the world, and the subsequent opening of more, their course has been stormy. Difficulties they have had to face included maintenance of acceptable university standards, communication with new rapidly growing topics relevant to the public health, and credibility to the hospital practitioner of clinical medicine.

C-E A Winslow ${ }^{3}$ was offered a fully fledged school of public health at Yale in the faculty of medicine. He chose instead to work under the clinical dean and with his faculty and called his group a department in the hope that social intercourse between population physician and personal doctor would be stimulating and educative-but it made little difference because in the end it is the willingness of people to talk to each other rather than the abolition of administrative structures which bridges gaps. One of the most important links is, nevertheless, with the clinical doctor.

The growth of public health depends on the continuous identification, integration, and dissemination of new sciences and new ideas. This cannot effectively occur in an institution where the departmental structure is too rigid. ${ }^{4}$ Yet strong integrated departments on a single location are essential once a vigorous new subject has been established. Perhaps some of those currently in the London School of Hygiene and Tropical Medicine no longer qualify. Gruenberg once wrote" : "I believe that the agencies organised in the name of public health have become too preoccupied with maintaining the activities they struggled to create, have too many personal service missions, and have already lost such a large part of their leading role in the struggle to improve health that we are wrong to rely exclusively upon them in the future. Just as something new was needed in 1916, so something new is needed in 1976."

The London School of Hygiene and Tropical Medicine, though centrally placed in the campus of the University of London, has never, apart from its association with the London Hospital for Tropical Diseases, had a formal link of any real permanency with the several local teaching hospitals, many experiments notwithstanding. In 1974 at the first reorganisation of the National Health Service it did not fit naturally into any of the four Metropolitan Regions but was forced mostly into the North-east Thames Region. Though this may perhaps have facilitated certain administrative arrangements, it created a highly anomalous relation with, among others, the academic departments of community medicine in the 12 undergraduate schools of medicine. The regional design had foreseen one medical school with its department of community medicine in each health region. In London there are several in addition to units from the London School of Hygiene and Tropical Medicine. The storm was weathered, albeit untidily, and the school burgeoned. In my view it would have made a lot of sense at that time (and it is not too late) to make the school a national institution within the University of London, above the intermittent warfare of the Thames health regions, and to encourage its members to create hospital ties such as are found convenient throughout the country-not necessarily in teaching schools. It cannot have been beyond the ingenuity of the higher echelons of the establishment to cope with many difficulties which need not have arisen had its fundamental differences from other schools been recognised by the university, the Civil Service, and the BMA.

Over the past couple of years, however, monetaristic policies have had far more drastic consequences both on the London School and on schools of public health in the United States than any relatively minor political issues that have preceded them. Thus the vice chancellor of the University of London solicited in May 1981 from Professor L P LeQuesne, the Dean of the Faculty of Medicine, a special report on the future of the school. ${ }^{6}$

Quite apart from the general problems which schools of public health have had to face, and have briefly been alluded to above, Le Quesne drew attention to two special difficulties which have confronted those in Keppel Street. Firstly, Governmental fiscal policy from 1980 had first increased dues payable by the students before cutting their domestic support for them and this had had a particularly drastic effect on a school which draws its students from 80 countries (including Britain). It is proposed that the University Grants Committee grant is withdrawn concomitantly, which could make an overall cut of $100 \%$ by $1982 / 3$. Despite the fact that some students are paying the top rate of $£ 6600$ a year the full annual economic cost of their training is not covered.

Secondly, these difficulties have in part been offset by a special supplementary grant from the University Grants Committee, by an increase of fee income, and a voluntary contribution from their own stipends of some $£ 40000$ from the staff of the school, leading to a probable increase in the student body of about $10 \%$, and an expected increase of considerably more than that in grant money. Nevertheless, these measures alone will not balance the books and the school faces an increasing deficit, which has led the dean ${ }^{6}$ to write, "The problem which now faces us is that we are threatened with a reduction in UGC grant which if applied inexorably will kill us ... Significant retrenchment would so undermine the structure of the school that closure would become inevitable."

Le Quesne entertains the breaking up of the school by creating attachments of relevant units to hospitals and colleges elsewhere, but on the basis of his inquiries he comes down strongly on "the total concept," and that the university should do all it can to sustain the school in its present form. He adds, however, that this cannot be done without modifications and contractions in the present arrangements.

With this conclusion I enthusiastically agree. Adding that it would require a review of the present policy both externally and internally and from the viewpoint of the university as a whole, Le Quesne goes on to describe medical microbiology (strangely the subject which Welch originally considered central to every school of public health) being taught by links with the Middlesex Hospital, University College Hospital, and University College. In this way modern technological advances in virology, immunology, and microbial genetics could all be included, and, it is proposed, the potential of an outstanding group working in medical microbiology could be created. 
But a group is not a school, and do outstanding schools ever exist in four parts, albeit three-quarters of a mile between each? North Wolfe Street in Baltimore and Shattuck Street in Boston, which separate Hopkins and the Harvard Schools of Public Health from their neighbouring hospitals, could be 10 miles wide so great is the breach to communication that they create. Pace Welch, does every school of public health need a department of microbiology anyway?

While questioning whether a school of tropical medicine is of any interest in Britain nowadays at all, Le Quesne asserts that those who believe it is should accept that the school's own contribution should be contracted and integrated with those of neighbouring institutions such as the department of clinical tropical medicine at St Pancras Hospital, University College Hospital, and the Public Health Laboratory Service at Colindale eight miles away. He even makes a very carefully guarded proposal that negotiations should be considered with the School of Tropical Medicine in Liverpool no less than 210 miles away to come into close collaboration with the school. Schismatisation of a centre, and with it schismatisation of training programmes, has a sad history. Students are likely to perform more satisfactorily in an established group in a constant environment with a single work bench of their own, a single locker to keep their equipment in, a single demonstrating staff whom they get to know and who gets to know them, and a familiar environment than if they are endlessly on the trot. Those of us who travel know only too well how disruptive a change of lodgings may be. Experiences with the modular system for professional training in community medicine in England and Wales have endorsed that. The disruption, wasted time, and full cost of inter-institutional movement are unlikely to have been included in many of the fiscal estimates available.

Two more departments in the London School of Hygiene and Tropical Medicine which are considered by Le Quesne for merging with others elsewhere in the university and perhaps transfer elsewhere are human nutrition to Queen Elizabeth College and occupational medicine and hygiene in Birmingham or Manchester, or both. This would make difficult, if not impossible, the attendance on an elective or compulsory basis at courses by students in these subjects, the core courses in epidemiology, medical statistics, and health services at the London School of Hygiene and Tropical Medicine which are currently thought to be important-and vice versa. Le Quesne looks on the London School of Hygiene and Tropical Medicine group in epidemiology as the strongest in the country. It will not be strengthened by a loss of its students in nutrition and occupational medicine. "There is a real need for a strong department in the school (which) side-by-side with the Department of Medical Statistics and Epidemiology is essential to the development of the subject in the country," Le Quesne writes of each. I would argue that such departments have replaced microbiology as being "central to every school of public health."

Again, I cannot but agree with him. Only one or two medical schools in the country can afford to support the critical mass of workers in these two topics which is of a size to permit the informal debate and discussion so important in furthering progress. The division of a department between "closely neighbouring schools" is most unlikely to allow this, and thus, as I have argued, to lead to disaster-to the spending of money without having anything to show for it.

The London School of Hygiene and Tropical Medicine is a unique national institution. It is appropriately placed in a university, and London, which is so readily accessible to the world at large, is an appropriate university for it. In its nature, however, it cannot be "squeezed" into the surrounding National Health Service regions, where the departments of community medicine in the many clinical schools already have difficulty enough in apportioning the necessary health service research work between themselves without intrusions from "big brother." Its clinical contracts could be negotiated nationally through specially established procedures which have proper contracts with those employed elsewhere. Most important of all the decision it makes must place as many complete and intact departments, albeit departments reduced in size, totally and entirely within the school. The calamity that must be avoided is the division of established departments into several components, none of which may be equipped for the management of a large class, each component being faced with the complex and elaborate task of co-ordinating its teaching with the other, and many of which will usually be geared to the fundamentally different world of teaching undergraduates.

Evans concluded in a very important review of schools of public health, which he properly looks upon as centres where theories of primary care are developed, in the following terms': " 'Health for All by the Year 2000' (has) created a new political awareness of health and drawn attention to the neglect of primary health care. . . the new economic reality facing most countries dictates that improvements in quality of services and population coverage will have to be achieved within the limits of existing budgets for recurrent expenditure. And ... there is an awakening of interest on the part of medical educators in a population-based strategy for the delivery of health care, and in more critical evaluation of the effectiveness of the expensive techniques used in diagnosis and treatment.

"Schools of public health might have been expected to be the ideal institutions to lead the process of change. Their academic structures, however, have not kept up with the rapidly changing face of public health, as it moved through environmental, microbiological, epidemiological, economic, sociobehavioral, and human-ecological stages of evolution. To provide leadership, schools of public health would have had to bring together knowledge and experience of current health operations with recent advances in biological, medical, and social sciences."

In my view the London School of Hygiene and Tropical Medicine does need reorganisation but it is far too important to be done away with by coup de grace, let alone the death of a thousand cuts. As many complete units should be retained in it as possible, and decisions as to those that are to survive should be made as soon as possible.

Health and health services are improved by work undertaken in schools of public health, and no private source of funds is going to bail them out. Public funds are essential.

Professor of Community Medicine,

RoY M ACHESON

University of Cambridge,

Addenbrooke's Hospital,

Cambridge CB2 2QQ

${ }^{1}$ Evans JR. Measurement and management in medicine and health services. Training needs and opportunities. New York: The Rockefeller Foundation, 1981.

2 Flexner S, Flexner JT. William Henry Welch and the heroic age of American medicine. New York: Viking Press, 1941.

${ }^{3}$ Acheson RM. The epidemiology of Charles-Edward Amory Winslow. Am $\mathcal{F}$ Epidemiol 1970;91:1-18.

4 Acheson RM. Community medicine: discipline or topic? Profession or endeavour? Community Med 1980;2:2-6.

5 Gruenberg EM. "Personal statement." New York: Higher Education for Public Health, 1976.

${ }^{6}$ Le Quesne LP. Report on the work of the school. London: London School of Hygiene and Tropical Medicine, 1981. 